\title{
Multidiscipilinary Apprach to Metastatic Skull Lesions; Endovascular Embolization, Gross Total Excision and Carnioplasty
}

\author{
MOHAMED SHADAD, M.D.; ESSAM ABD EL-HAMID, M.D. and MAHMOUD SHOAIB, M.Sc. \\ The Department of Neurosurgery, Faculty of Medicine, Tanta University
}

\begin{abstract}
Background: Metastatic skull lesions are being more frequently diagnosed. There are many reports of skull metastases from approximately all cancer types. Clinical presentation of these lesions includes cosmetic complaints and neurological deficits attributable to site of the lesion. Management modalities of metastatic skull lesions include radiation therapy, chemotherapy, pre-operative endovascular embolization and surgical excision.
\end{abstract}

Aim of Study: The aim of this work is to evaluate the outcome of metastatic skull tumor embolization, gross total resection and cranioplasty.

Patient and Methods: This study included 8 patients with metastatic calvarial skull lesions admitted to Department of Neurosurgery, Tanta University between January 2015 and March 2018. All patients were subject to 2 stages of management; endovascular embolization, surgical excision and cranioplasty.

Results: This study included 8 patients (4 male and 4 female) with main age 53 years. Pathologic types included; 3 patients with renal cell carcinoma, 2 with cancer breast, 2 with hepatocellular carcinoma and 1 with thyroid adenocarcinoma. All patients were presented for cosmetic reason except one patient who had right hemiparesis. In all patients, near total pre-operative embolization was done without techniquerelated morbidity or mortality. Gross total excision was possible in all patients. Excision was followed by cranioplasty using a titanium mesh. Operative complications included aseptic necrosis of the edge of the wound in one patient and healed in 1 month by daily dressing. One patient died because of unrelated cause 2 days post-operatively.

Conclusion: Multidisciplinary approach to metastatic skull lesions by adding pre-operative embolization to excision and cranioplasty to such lesions provides better chances of gross total excision with minimal morbidities.

Key Words: Skull-Calvarial-Metastasis - Endovascular embolization - Surgical excision - Titanium Cranioplasty.

Correspondence to: Dr. Mohamed Shadad, The Department of Neurosurgery, Faculty of Medicine, Tanta University

\section{Introduction}

METASTATIC skull lesions are being more frequently diagnosed due to increased survival of patients harboring malignant tumors in any other part of the body, and advancement achieved in the diagnostic modalities used in the diagnosis and assessment of these lesions. There are many reports of skull metastases from nearly all types of cancers. Common cancers with metastases to the skull include cancers of the breast in females, cancers of the prostate in males and cancers of the liver, lung, thyroid, kidney and colon in common. The hematogenous route is the most common route of spread of these cancers to the skull [1]

Clinical presentation of these lesions includes cosmetic complaints of masses protruding from the skull and manifestations attributable to the location of the lesion which occur only in cases of dural invasion, obstruction of related venous sinuses and compression of eloquent brain areas. There are some reports of metastasis without a known primary focus [2].

The modalities of imaging used in assessment are not different from those used for parenchymal brain tumors. Computed Tomography (CT) is used to assess the related skull bone. As usual, CT is one of the best modalities to show the bony anatomy and changes occurring in it. Magnetic Resonance Imaging (MRI) is the modality of choice especially with the addition of intravenous contrast. It accurately demarcates the lesion and helps in assessment of invasion of the various nearby structures; namely the dural sinuses and cerebral cortex. CT angiography or conventional angiography can be used to show the vascularity of the lesion, its feeding arteries and the condition of the nearby sinuses [3-5]. 
It has to be noted that the tumor blush associated with metastatic lesions may be similar to that of meningiomas. It is characterized by early appearance of the blush in the late arterial phase and its persistence in the capillary and venous phases. It is often described as "early come, late go" blush. Selective embolization of the tumor feeders is considered a good adjunct to gross total resection. Differential diagnosis of skull metastases includes primary tumors of skull (e.g., osteomas, chordomas, chondrosarcomas, dermoid cysts, and epidermoid cysts) and benign tumor-like lesions (e.g., hyperostosis, fibrous dysplasias, and eosinophilic granulomas) [6]

Management modalities of metastatic skull lesions include radiation therapy, chemotherapy, preoperative endovascular embolization and surgical excision. Surgery should be considered when one or more of the following is present, (1) When there is a painful mass, (2) When massive destruction of bone (and dura) occurs, (3) When a neurological deficit is present (4), When solitary metastasis is present, (5) For cosmetic purpose, (6) When confirmation of the diagnosis is warranted. Especially when the primary lesion is controllable with good life expectancy. Surgery aims to resect the infiltrated bone and replace it by bone-cement or titanium mesh. If the dura is infiltrated, it needs to be both resected and replaced [7]. The main benefit of embolization is to induce tumor necrosis with minimization of intraoperative blood loss and overall operative time [8].

\section{Aim of the work:}

The aim of this work is to evaluate the outcome of metastatic skull tumor embolization, gross total resection and cranioplasty. In this study, we will discuss the topic of metastatic skull lesions which are present in the calvarium and not in the skull base.

\section{Patients and Methods}

This study included 8 patients with metastatic calvarial skull lesions admitted to Department of Neurosurgery, Tanta University between January 2015 and March 2018. The study included patients presented by neurological deficit or cosmetic complain. Patients with skull base metastasis, patients in bad general condition or those with short life expectancy were excluded from our study.

All patients were subject to neurological examination followed by imaging by CT, MRI and conventional angiography. Pre-operative detailed explanation of the techniques, expected results, possible complications and various interventions were relayed to the patient and relatives and informed consent was signed upon agreement.

All patients were subject to 2 stages of management; endovascular embolization, surgical excision and cranioplasty. Pre-operative trans-arterial embolization was done in all patients prior to surgery. Microsurgical excision and skull reconstruction were done as second step.

Embolization techniques; patients were operated upon in the neuroangiography suite under general anesthesia. Standard trans-femoral approach was used in all patients. Materials used in embolization include 5-F or 6-F guiding catheter (Guider soft tip, Stryker), flow directed microcatheter (Magic $1.8 \mathrm{~F}, \mathrm{Balt})$ which is navigated with the aid of a micro guide wire (Hybrid, Balt). The main material used in embolization was Polyvinyl alcohol particles (Contour, Stryker) with different sizes ranged from 45 to 450 microns. Embolization usually begins with the smallest size to obliterate the capillary bed of the tumor followed by larger particles to occlude larger intra-tumoral arterioles in a progressive fashion. Super selective catheterization of feeding arteries and free flow embolization techniques were used to obliterate tumor blush at control images. No occlusion of parent feeding arteries as this leads to recruitment of collateral blood supply to tumor.

Surgical techniques; the aim was to perform gross total excision of the lesions. This was done by aggressive resection of the lesion, removal of marginal bone tissue and resection of any infiltrated dura mater or skin. Excision was followed by titanium mesh cranioplasty in all patients. This type of mesh can be molded to take a good contour, hard enough to give protection to underlying structures, can be fixated well to the surrounding healthy bone edges and its pores allow vascularization of the skin flap from underlying tissues. Fashioning of the skin flap was planned to enable gross total resection with safety margin taking in consideration ensuring good vascularization of the skin flap to avoid post-operative necrosis. We do not usually do piecemeal debulking for such lesions and we preferred dissection at tumor margins to minimize blood loss.

\section{Results}

In this study, 8 patients including 4 males and 4 females ranged between $40-67$ years with main age 53 years. Pathologic types included; 3 patients ( 2 female \& 1 male) with renal cell carcinoma, 2 female with cancer breast, 2 male with hepatocellular carcinoma and 1 male with thyroid adenocar- 
cinoma (Table 1). Three patients had parietooccipital lesion, two patients had frontal lesions, two had parietal lesions and one patient had frontoparietal lesion. All patients were presented for cosmetic reason except one patient had right hemiparesis.

Table (1): Pathologic types of metastatic tumors.

\begin{tabular}{lcc}
\hline Type of tumor & Male & Female \\
\hline Renal cell carcinoma & 1 & 2 \\
Cancer breast & 0 & 2 \\
Hepatocellular carcinoma & 2 & 0 \\
Thyroid adenocarcinoma & 1 & 0 \\
\hline
\end{tabular}

In all patients, pre-operative transarterial embolization was done without technique-related morbidity or mortality. Near total embolization was done in all cases. The feeding arteries represented branches of the External Carotid Artery (ECA) namely, in order of frequency, middle meningeal artery, occipital artery, superficial temporal, artery accessory meningeal artery and other feeders from meningeal branches of Internal Carotid Artery (ICA). In one patient, a vascular variant was found which is a recurrent middle meningeal artery as a branch of the ophthalmic artery. Embolization through this dangerous feeder was also done without affection of vision (Table 2).

Table (2): Tumor feeders.

\begin{tabular}{lcc}
\hline Branches & Patients No. & $\%$ \\
\hline Middle meningeal artery & 8 & 100 \\
Occipital artery & 7 & 87.5 \\
Superficial temporal artery & 6 & 62.2 \\
accessory meningeal artery & 4 & 50 \\
Others & 4 & 50 \\
\hline
\end{tabular}

Mean operation time was $2^{1} / 2$ hours. Gross total excision was feasible in all patients and was made easy by the aid of preoperative embolization. Excision was followed by titanium mesh cranioplasty. Intraoperative blood loss for the excision and cranioplasty ranged from $500-1200 \mathrm{ml}$. Two patients required transfusion of one pack of blood during surgery. Good cosmoses was achieved as evidenced by the contour of the skull. The case of pre-operative hemiparesis improved and was ambulant in the 2 weeks early follow-up.

Operative complications included aseptic necrosis of the edge of the wound in one patient and healed by daily dressing. Healing took about 1 month to occur with no adverse events. one patient with metastatic hepatocellular carcinoma developed intestinal obstruction from strangulated umbilical hernia 2 days post-operatively, operated by general surgery team and deteriorated after this and died 2 days later. Follow-up CT brain was unremarkable.

CT brain with 3D reconstruction was used as routine follow-up immediate post-operatively and at hospital discharge. After hospital discharge MRI brain used routinely to rule out any new manifestations.

During follow-up period, patient with hepatocellular carcinoma had local recurrence 9 months after surgery while other 7 cases there was no recurrence in follow-up period. Primary tumor and its behavior, degree of lymphatic or hematogenous spread, response to treatment including radiotherapy and chemotherapy are all factors affecting prognosis but in our series we just highlight technique for treatment of calvarial metastases.

\section{Discussion}

The skull represents a frequent site for tumor metastasis. Radiation has been proposed by some as the treatment modality of choice for such lesions associated with late stage cancers. Gross total resection has also been advocated especially with control of the primary disease. Because most of skull metastasis are vascular, pre-operative embolization can be done to decrease blood loss and save time needed for hemostasis $[\mathbf{3 , 8}]$.

In this study we discuss multidisciplinary approach to calvarial metastasis by pre-operative tumor embolization followed by gross total excision and cranioplasty and its effect on cosmetic and functional outcome in these patients.

Our series included 8 patients only because we were meticulous in patient selection, we excluded skull base lesions and cases of brain invasion, we also excluded patients in bad general condition, short life expectancy and uncontrolled primary. Michael et al., reported that only 27 of 900 patients with calvarial metastases underwent surgery between 1993 and 1999 [9]. Patients presenting with skull metastases are often in an advanced disease stage, but surgery can improve symptoms rapidly and effectively with low morbidity, especially, patients with neurologic deficit should be prepared for early surgery [10]. This results coincides with Roukoz B. et al., 2011 as they reported that only a small number of patients with metastasis to the skull are considered candidates for surgical excision. These patients are selected based on clinical and functional status; extent of primary and metastatic diseases; radiographic studies; and the tumor's histopathology, biologic nature, and response to previous therapies [11]. 
There are few articles in the published medical literature specifically addressing this topic. Pallini and colleagues reported their experience in the management of 7 cases with skull metastases. The primary tumors were lung cancer (3 cases), prostate cancer ( 2 cases), melanoma ( 1 case), and hepatocellular carcinoma ( 1 case) [12]

In our study, all patients were presented for cosmetic reason except one patient $(12.5 \%)$ had right hemiparesis. Stark et al., 2003 recorded that two patients of twelve (16.6\%) had neurological deficit [10]. Mitsuya et al., 2011 reported the same results. They concluded that patients with calvarial circumscribed metastases usually have no symptoms. Calvarial locally invasive metastases caused local pain and swelling in five patients (18\%). Calvarial diffuse invasive metastases caused headache and nausea in four patients $(11 \%)$ because of dural and subdural invasion [4]. Stark et al., 2003 also concluded that most metastatic skull lesions are asymptomatic, although they can cause grave symptoms due to compression of dural sinuses and/or cranial nerves [10].

The most common primary tumor in our study was renal cell carcinoma followed by breast cancer because they have good prognosis and were ideal cases for selection in our study. Mitsuya et al., reported breast cancer as the most frequent source of skull metastases both for calvarial and skullbase metastases. This contributed to the large preponderance of female vs. male patients $(7: 3)$ in their study [4]. Hsieh CT et al., 2007 reported that metastasis to the skull frequently occurs in patients with lung, breast and prostate cancer [12]. However, skull metastases from Hepatocellular Carcinoma (HCC) have been rarely reported, in our study we had two patients had HCC. This me be explained by increased incidence of HCC in Egypt due to large population with hepatitis $\mathrm{C}$ virus infection. Hsieh et al., 2007 reviewed the literature on skull metastasis from HCC and reported a case of a 46year-old male, who was diagnosed as HCC and was operated on by trans-arterial embolization and surgical excision [13]

Mean operation time was 150 minutes because we saved a lot of time needed for hemostasis. Bleeding was minimal due to efficient pre-operative embolization that allow easy dissection of the tumor. Gross total resection was achieved in all cases. Different materials have been used in reconstruction of the bone defects left behind after excision of skull lesions. Pre-operative embolization decrease the vascularity of the tumor and reduce intraoperative blood loss, permitting a more com- plete surgical excision. With better control of intraoperative bleeding, less coagulation is needed, and the risk of thermal injury is diminished $[\mathbf{1 4 , 1 5}]$.

We used titanium mesh in all cases because of it has strong material, good deformability, easy applicability, better cosmetic results and above all compatible with radiotherapy if needed.

One patient had pre-operative hemiparesis which improved and the patient was ambulant in the early post-operative period. Aseptic necrosis of the edge of the wound occurred in one patient which was managed by daily dressing. Healing took about 1 month to occur with no adverse events. This probably occurred due to the usage of the smallest available size of particles associated with a large flap of the scalp. These are 2 factors probably affected the blood supply of the flap.

Only one mortality in our series, the patient had metastasis from hepatocellular carcinoma, patient had intestinal obstruction from strangulated umbilical hernia and operated by general surgery team and died two days later after deterioration of the general condition. CT brain done before and after surgery had unremarkable findings. In the past and because of the short survival of patients with HCC, their clinical presentations were mostly related to the primary cancer itself. However, advances in the treatment of HCC have made it possible for the patient to survive longer, and as a result, distant metastasis from $\mathrm{HCC}$, including bone metastasis, has increased and attracted more attention than before [16].

\section{Conclusion:}

Patients with skull metastases usually present with cosmetic problems and rarely with neurologic deficits. They can benefit from early diagnosis of the tumor, and gross total excision with satisfactory outcome. Multidisciplinary approach by adding pre-operative embolization to surgical excision and cranioplasty to such lesions provides benefits to the patients by offering better chances of gross total resection with minimal morbidities attributable to the applied interventions. It also offers benefits to the surgeon by facilitating various operative steps owing to better achievement of tumor devascularization, easier hemostasis and good cosmetic outcome. This group of patients should be selected and managed with great caution to have better outcomes. It is difficult to say anything sensible when discussing prognosis, as it is clearly $\&$ hugely affected by the degree of systemic disease and the response of the primary tumor to therapy. 


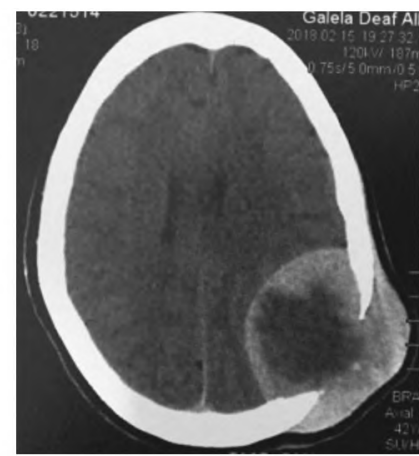

Enhanced axial CT showing tumor with bone erosion

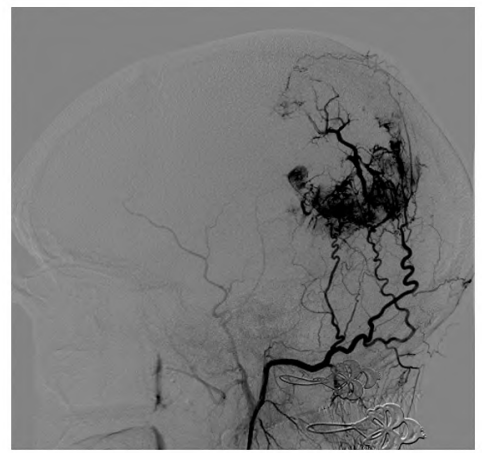

RT occipital A LAT pre showing tumor blush

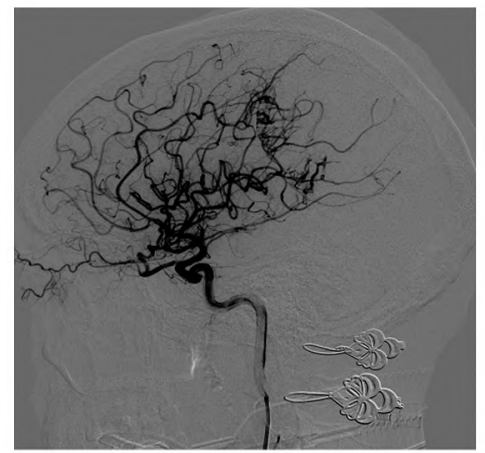

Aberrant origin of middle meningeal A from ophthalmic A

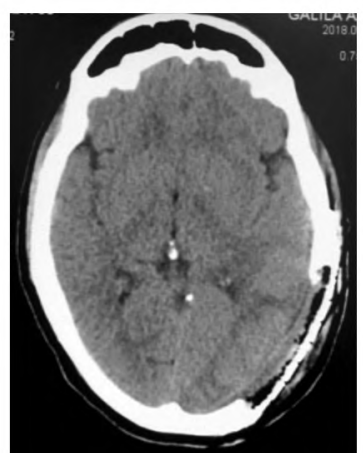

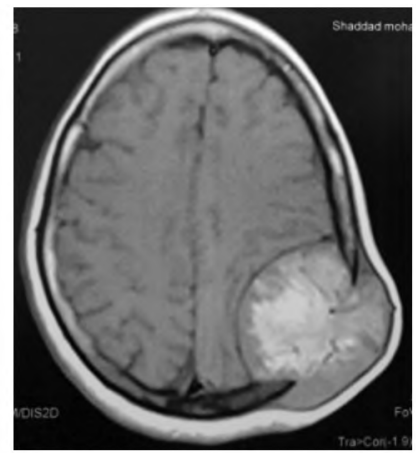

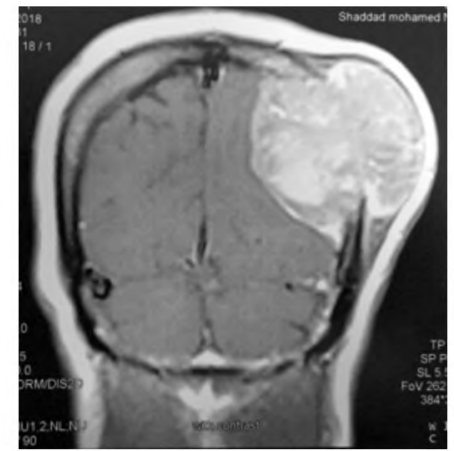

Enhanced T1 MRI showing tumor mass in different planes

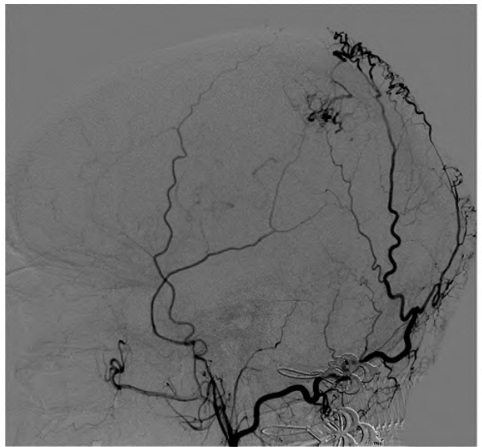

LT occipital A LAT pre showing tumor blush

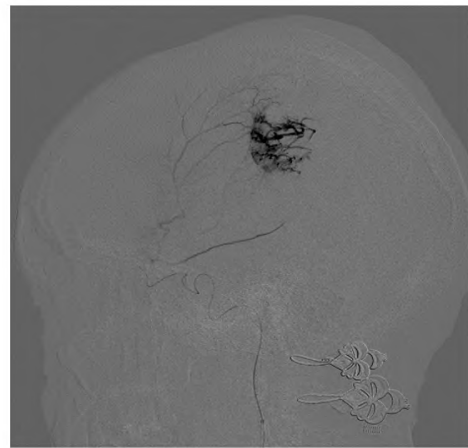

Superselective catheterization of MMA

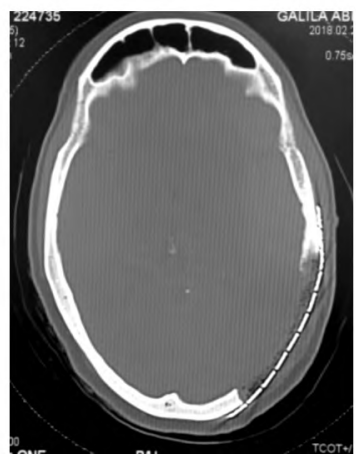

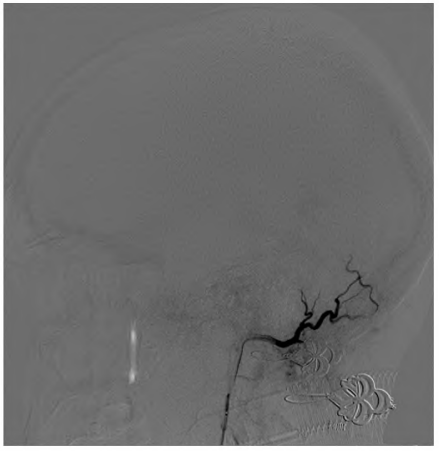

RT occipital A LAT post showing obliteration of tumor blush

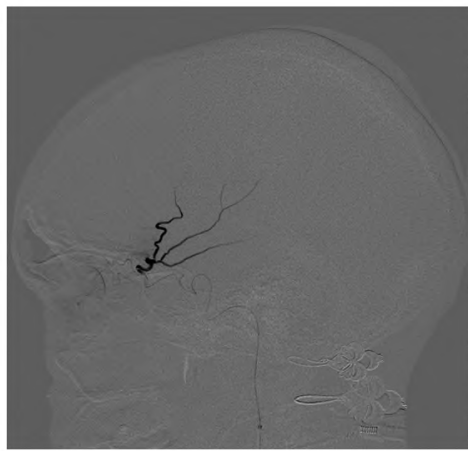

Obliteration of tumor blush in compartments supplied by MMA

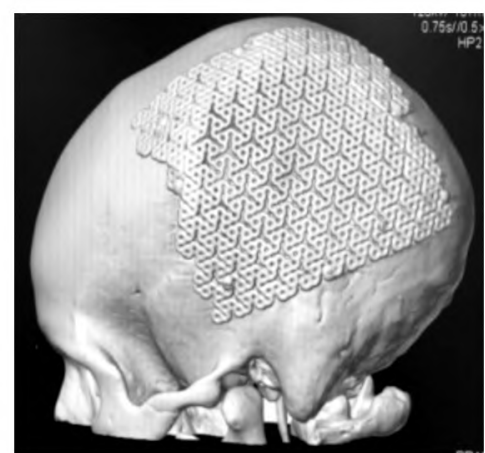

Axial CT with bone window and 3D reconstruction showing removal of the tumor \& dural and bony attachments and cranioplasty with titanium mesh

Case (1): Female patient 48 years old presented with metastatic renal cell carcinoma. Transarterial embolization was done followed by surgical removal of the tumor with its dural \& bony attachments. Finally cranioplasty with titanium mesh was done. 


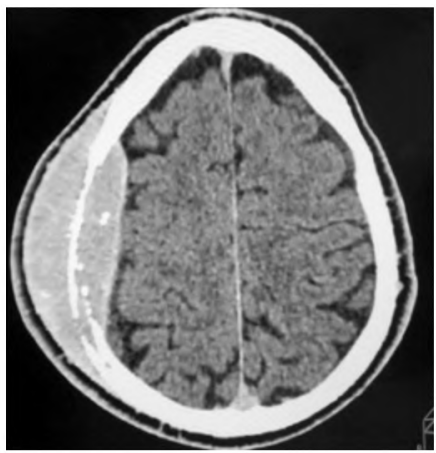

Axial enhanced CT showing tumor mass

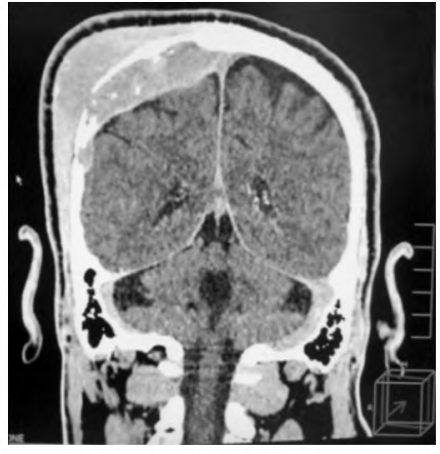

Coronal enhanced CT showing tumor mass

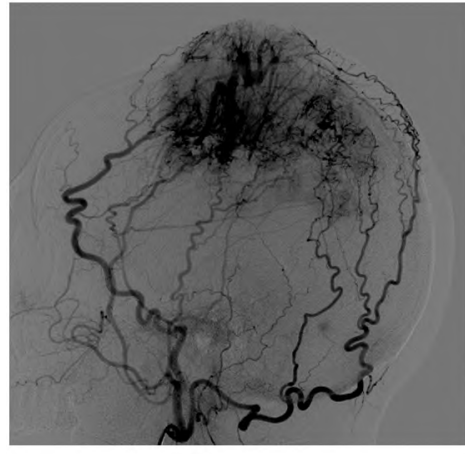

RT ECA LAT pre showing tumor blush

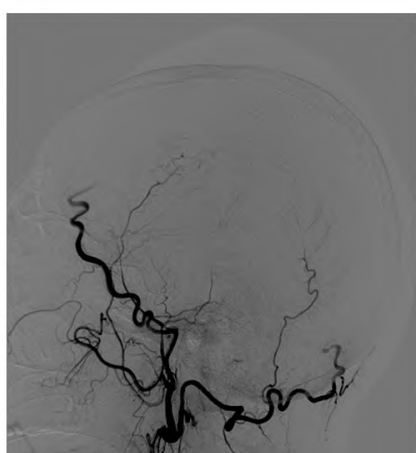

RT ECA LAT post showing obliteration of tumor blush

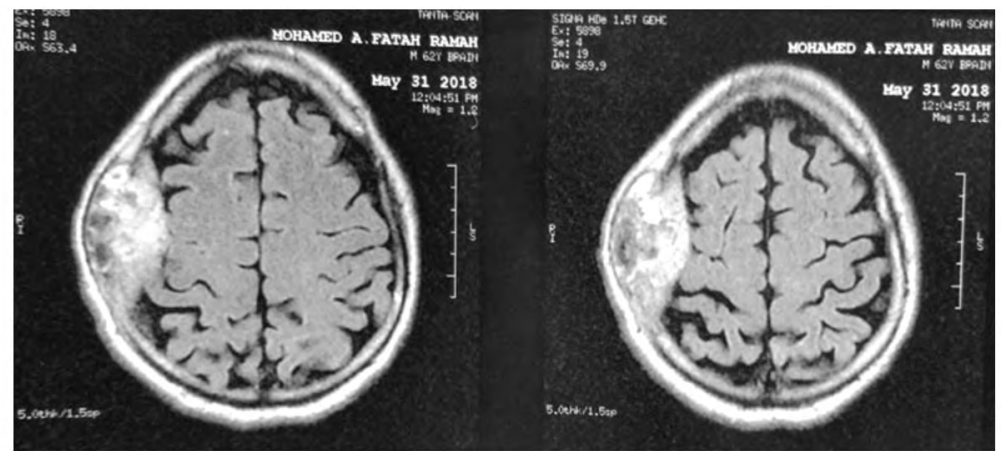

Axial enhanced T1

showing tumor mass

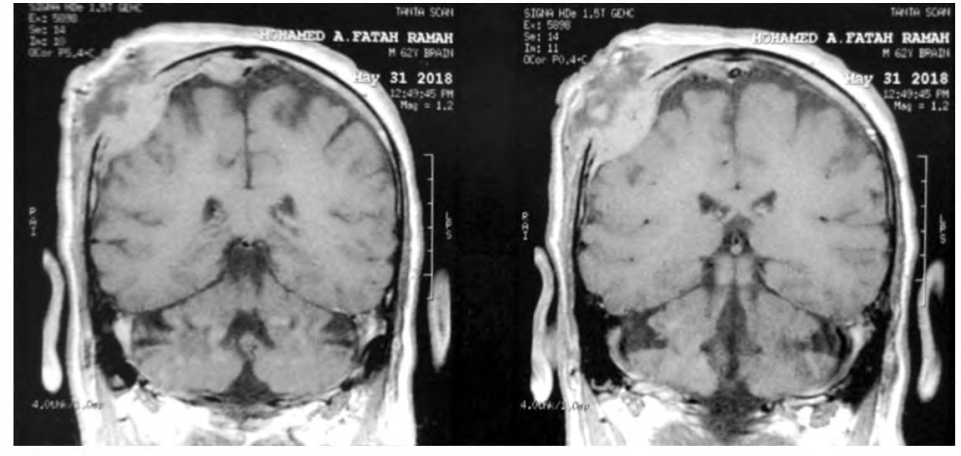

Coronal enhanced T1

showing tumor mass

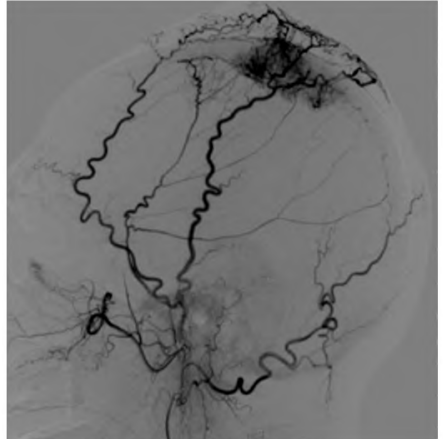

LT ECA LAT pre showing tumor blush

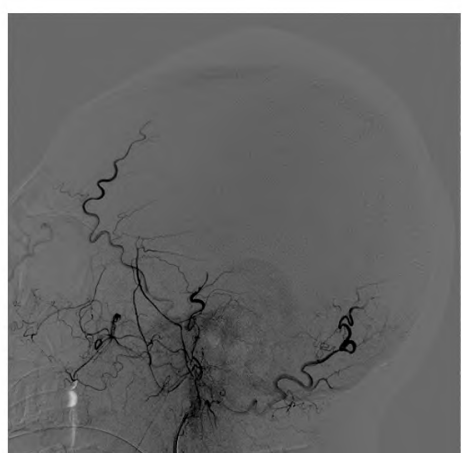

LT ECA LAT post showing obliteration of tumor blush

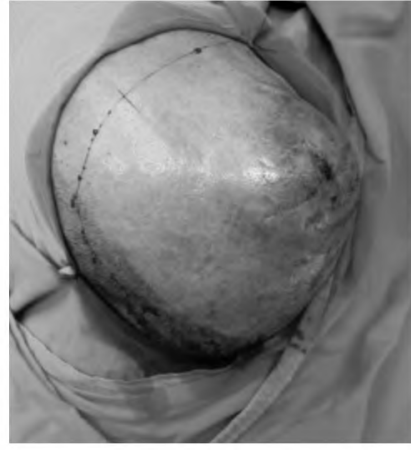

Pre-operative image show tumor mass

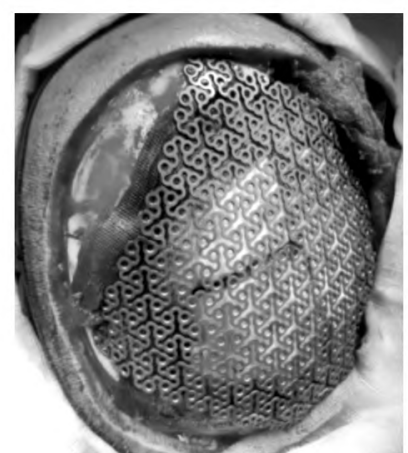

Intraoperative image show titanium mesh after tumor resection

Case (2): Male patient 60 years old presented with metastatic hepatocellular carcinoma. Transarterial embolization was done followed by surgical removal of the tumor with its dural \& bony attachments. Finally cranioplasty with titanium mesh was done. 


\section{References}

1- SHEN J., WANG S., ZHAO X., SHAO X., JIANG X., DAI Y., et al.: Skull metastasis from follicular thyroid carcinoma: Report of three cases and review of literature. Int. J. Clin. Exp. Pathol., Nov. 1; 8 (11): 15285-93. e Collection 2015.

2- HAN S., ZHANG X.H., LV T. and HAN D.H.: Skull Metastasis from the Liver: Case Report and Literature Review. World Neurosurg., 108: 989 e15-989 e18, 2017.

3- XU J., YI H., LI X., CHEN W. and XU J.: Surgical treatment of lateral skull base lesions and reconstruction of the skull base: A report of 20 cases. Acta Otolaryngol., Feb., 137 (2): 131-5, 2017.

4- MITSUYA K., NAKASU Y., HORIGUCHI S., HARADA H., NISHIMURA T., YUEN S., ASAKURA K. and ENDO M.: Metastatic skull tumors: MRI features and a new conventional classification. J. Neurooncol., 104 (1): p. 239-45, 2011.

5- MURAKAMI R., KOROGI Y., SAKAMOTO Y., TAKHASHI M., OKUDA T., YASUNAGA T., NISHIMURA R. and YOSHIMATSU S.: Skull metastasis from hepatocellular carcinoma. CT, MR and angiographic findings. Acta Radiol., 36 (6): p. 597-602, 1995.

6- STARK A.M., EICHMANN T. and MEHDORN H.M.: Skull metastases: Clinical features, differential diagnosis, and review of the literature. Surg. Neurol., 60 (3): p. 21925; discussion 225-6, 2003.

7- ABE T., MATSUMOTO K., SUNAGA S., DOHI K., HANAKAWA K., SHIMAZU M., et al.: Metastatic skull tumors from cancers associated with subcutaneous mass lesions. No To Shinkei, 51 (4): p. 353-9, 1999.

8- MOSCOTE-SALAZAR L.R., BALDERRAMA J., ALVISMIRANDA H.R., LEE A. and ALCALÁ-CERRA G.:
Endovascular management of skull base tumors. A practical review on literature]. Rev. Med. Inst. Mex. Seguro. Soc., 52 (4): p. 422-8, 2014.

9- MICHAEL C.B., GOKASLAN Z.L., DeMONTE F., McCUTCHEON I.E., SAWAYA R. and LANG F.F.: Surgical resection of calvarial metastases overlying dural sinuses. Neurosurgery, 48 (4): p. 745-54; discussion 754-5, 2001.

10- STARK A.M., EICHMANN T. and MEHDORN H.M. Skull metastases. Clinical features, differential diagnosis, and review of the literature. Surg. Neurol., Sep., 60 (3): 219-25; discussion 225-6, 2003.

11-ROUKOZ B. and FRANCO DeMONTE: Management of Skull Base Metastases. Neurosurgery clinic, (22): 61-6, 2011.

12- PALLINI R., SABATINO G., DOGLIETTO F., et al.: Clivus metastases: report of seven patients and literature review. Acta Neurochir (Wien), 151 (4): 291e6 [discussion: 296], 2009.

13- HSIEH C.T., SUN J.M., TSAI W.C., TSAI T.H., CHIANG Y.H. and LIU M.Y.: Skull metastasis from hepatocellular carcinoma. Acta Neurochir. (Wien). Feb., 149 (2): 18590, 2007.

14- HILAL S.K. and MICHELSEN J.W.: Therapeutic percutaneous embolization for extra-axial vascular lesions of the head, neck, and spine. J. Neurosurgery, 43: 275-87, 1975.

15- VALVANIS A.: Pre-operative embolization of the head and neck: Indications, patient selection, goals and precaution. AJNR Am., 7: 943-9, 1986.

16- FUKUTOMI M., YOKOTA M., CHUMAN H., HARADA H., ZAITSU Y., FUNAKOSHI A., et al.: Increased incidence of bone metastases in hepatocellular carcinoma. Eur. J. Gastroenterol. Hepatol., 13 (9): p. 1083-8, 2001. 


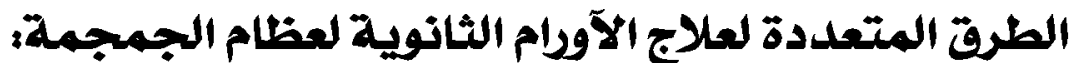

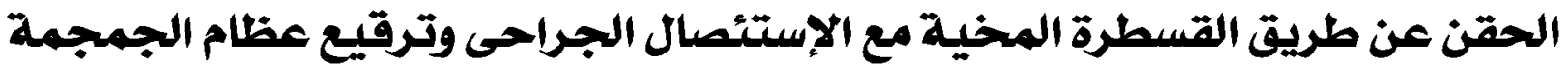

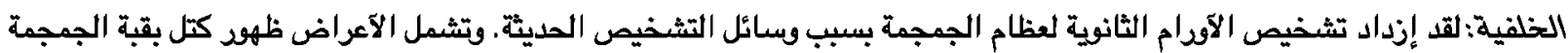

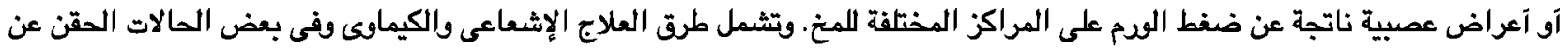
طريق القسطرة المخية والإستئصال الجراحي.

الهدف : تقييم علاج الآورام الثانوية للجمجمة عن طريق توجه مكثف يشتمل على حقن هذه الآورام عن طريق القسطرة المخية ثم إستئصال

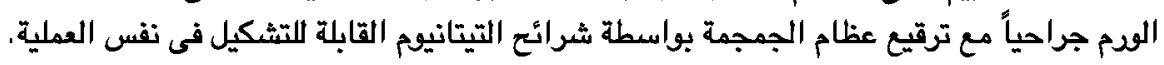

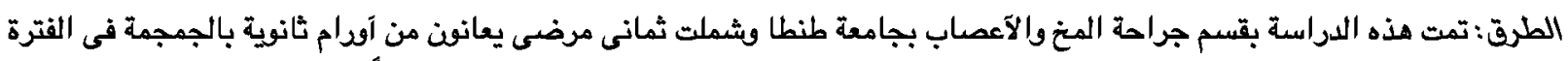

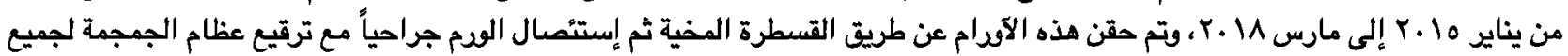
المرضى.

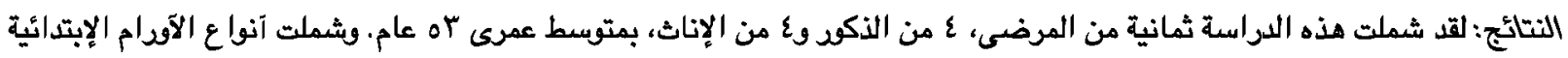

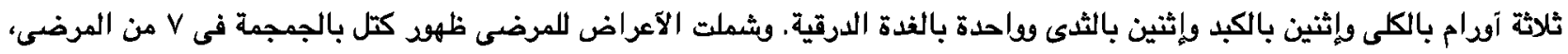

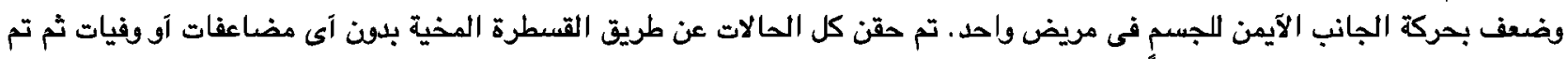

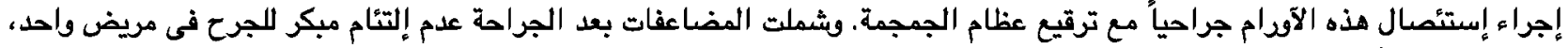

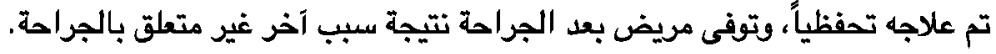

الإستتاجات: تطبيق تقنية حقن الآورام الثانوية لعظام الجمجمة عن طريق القسطرة المخية يعطى المريض فرص آفضل لإستئصالها

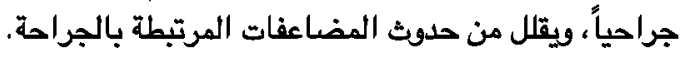

